\title{
The human body through the El Greco's eyes
}

\author{
Juan F. Martínez-Lage • Claudio Piqueras • \\ Miguel-Angel Pérez-Espejo
}

Published online: 10 July 2014

(C) Springer-Verlag Berlin Heidelberg 2014

\section{Brief biography of El Greco [4-7]}

Domenikos Theotokópoulus was born in Candia (1541, exact date unknown), Crete, which in that epoch belonged to the Republic of Venice. He is best known by the nickname of El Greco (the Greek) in reference to his birthplace. In Greece, he was educated in the post-Byzantine art and at the age of 26 years he traveled in Venice and then in Rome where he received influences from Mannerism and Renaissance styles. Looking for fortune, he moved to Madrid and then to Toledo (Spain) in 1577. In that time, Toledo that counted with more than 60,000 inhabitants was one of the largest cities in Europe. In the 1570s, the Monastery of El Escorial was being built and apparently there existed a lack of artists and painters to decorate the palace. El Greco initially made several paintings for Santo Domingo el Antiguo church in Toledo, probably protected by his close friend Luis de Castilla, dean of Toledo's Cathedral. Subsequently, he tried to obtain the favor of King Philip II of Spain, but two of his works (Allegory of the Holy League and Martyrdom of Saint Maurice) were not completely approved by the king and he did not receive further royal commissions. Accordingly, he installed his workshop definitively in Toledo where he worked and lived until his death (7 April 1614).

\section{El Greco's works [4-7]}

During his late years, El Greco hired an assistant and produced many paintings, altar frames, and some sculptures. His bestknown work is the Burial of the Count of Orgaz that remains in its original place, Santo Tomé Church in Toledo (Fig. 1). El

J. F. Martínez-Lage $(\bowtie) \cdot C$. Piqueras $\cdot$ M.-A. Pérez-Espejo

Regional Service of Neurosurgery, "Virgen de la Arrixaca"

University Hospitals, 30120El Palmar, Murcia, Spain

e-mail: juanf.martinezlage@gmail.com
Greco mastered two main lines of paintings: religious scenes and portraits of notable people of the epoch. Religious and other paintings can be admired in many cities of Spain (Palencia, Oviedo, Bilbao, Andújar, Cádiz, and Seville), being the Museo de El Prado in Madrid where most of his production is exhibited. On the other hand, numerous oils can also be visited in diverse museums and art galleries all over Europe (Saint Petersburg, Amsterdam, Stockholm, Copenhagen, Athens, Dresden, Munich, Modena, Naples, Florence, Budapest, Bucharest, Prague, Paris, Edinburgh, London...) and of the USA and Canada (New York, Minneapolis, Philadelphia, San Francisco, Boston, Omaha, Cleveland, Kansas City, Chicago, Fort-Worth, Cincinnati, Toledo-Ohio, Washington, and Los Angeles). Some other paintings are conserved in private collections. During the present year (2014), the cities of Toledo and Madrid are celebrating the 400th anniversary of El Greco's death and have gathered many of these scattered works in several museums and exhibition halls [4].

\section{El Greco's style}

Observing many of his paintings, one can follow the evolution of the El Greco's style (Fig. 2). During his Italian stay, he was influenced by two genii of painting, Titian and Tintoretto and probably also by Michelangelo and Rafael [7]. However, in the Spanish period, he developed a new and different style that is characterized by the slender and elongated figures (Fig. 3 and cover figure, Fig. 4) probably influenced by Tintoretto and by his domain of striking colors probably influenced by Titian [7]. In many religious works, one can also observe the existence of two planes, the upper part that depicts the heavenly vision and the lower part that depicts the human representation. He died without leaving a solid school of followers; only his son Jorge Manuel Theotokópoulus and a few unimportant painters made copies of his works. 


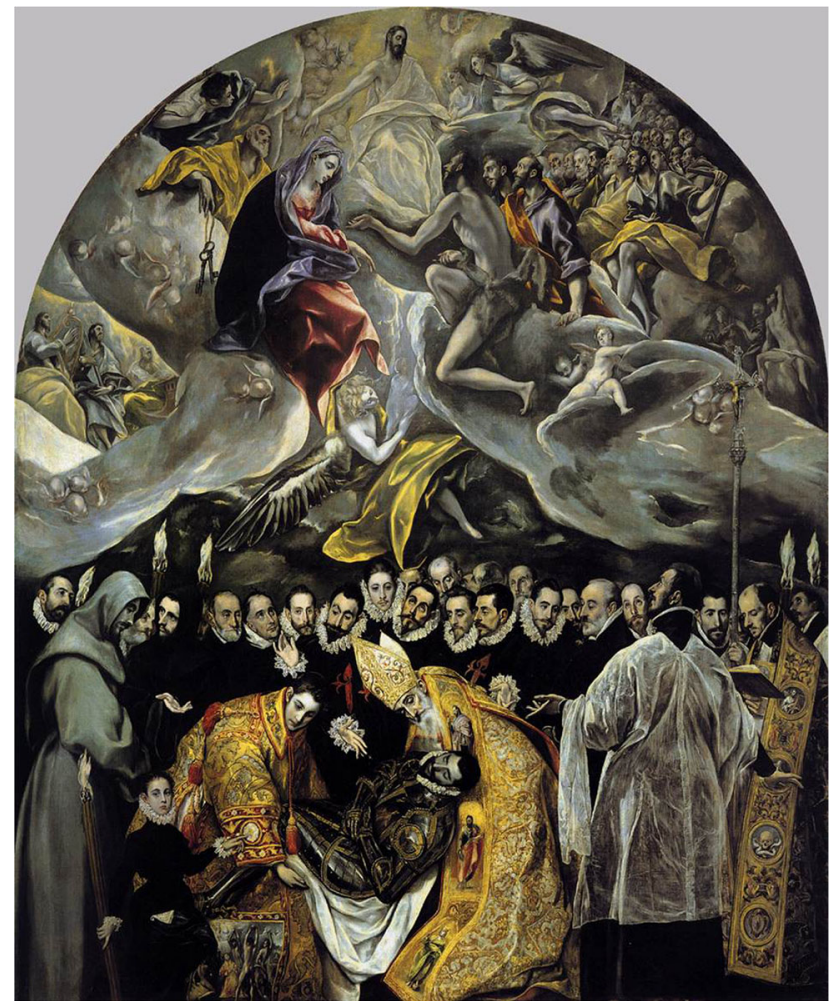

Fig. 1 Photograph of the Burial of the Count of Orgaz, Church of St. Tomé, Toledo, Spain
Some people appearing in the works of El Greco apparently were inspired from living persons of the author's environment, as happens with the face of the Virgin that closely resembles that of the painter's companion (Fig. 5). Children and childish figures (Figs. 3, 4, 6) also showing striking faces and hands, with thin and elongated fingers, evoke the features of Marfan syndrome and those of marfanoid trait [3]. The El Greco's inclination for painting tall and elongated figures has even been attributed to the painter's defective vision such as progressive astigmatism although most researchers and art critics do not share this opinion [1]. Most probably, these intentional style changes are due to esthetic and expressive considerations intended to increase the spirituality of the figures. This tendency to depict thin and elongated images was also applied in representing children adolescents and even angels (Fig. 3, 4, 6).

Some researchers have stressed the personal style of El Greco's paintings that is hardly comparable to that of others. For many years, El Greco's art was disdained because his work did not follow the rules and principles of recognized styles. It was not until the beginning of the twentieth century that his work was best fully appreciated after the work of Cossío [2]. El Greco inspired modern expressions of art, especially cubism and expressionism. Some works of Pablo Picasso, especially during his Blue Period, show this
Fig. 2 Photographic composition of the evolution of faces in the El Greco's paintings. a Saint Sebastian, b Jorge Manuel Theotokópoulus, the artist's son, c Jesus Christ face, $\mathbf{d}$ the Virgin Mary
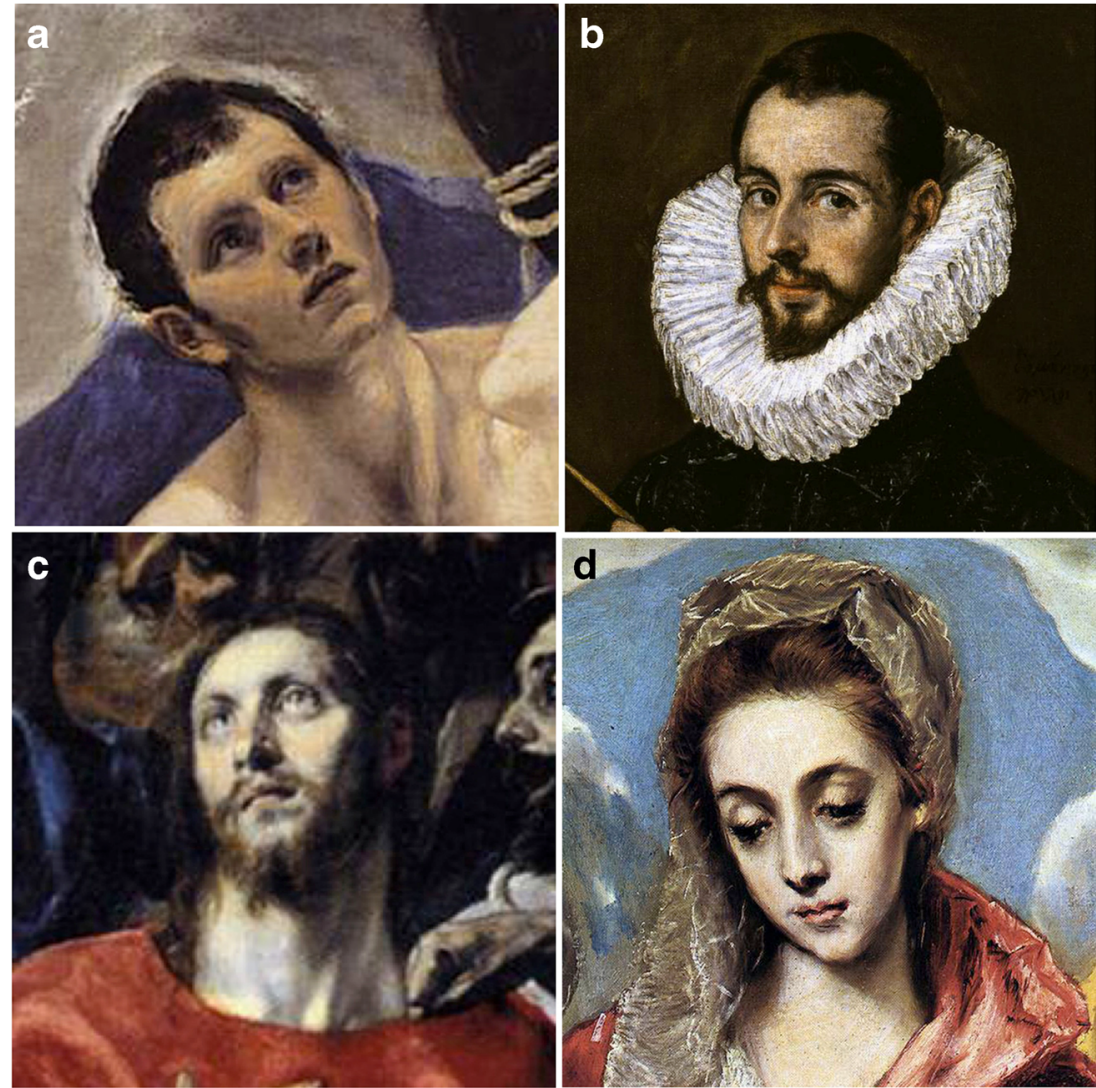
Fig. 3 and cover figure: Details of several paintings of St. John the Evangelist, from: left St. John and St. Francis, center St. John, right the Crucifixion (El Prado

Museum, Madrid)
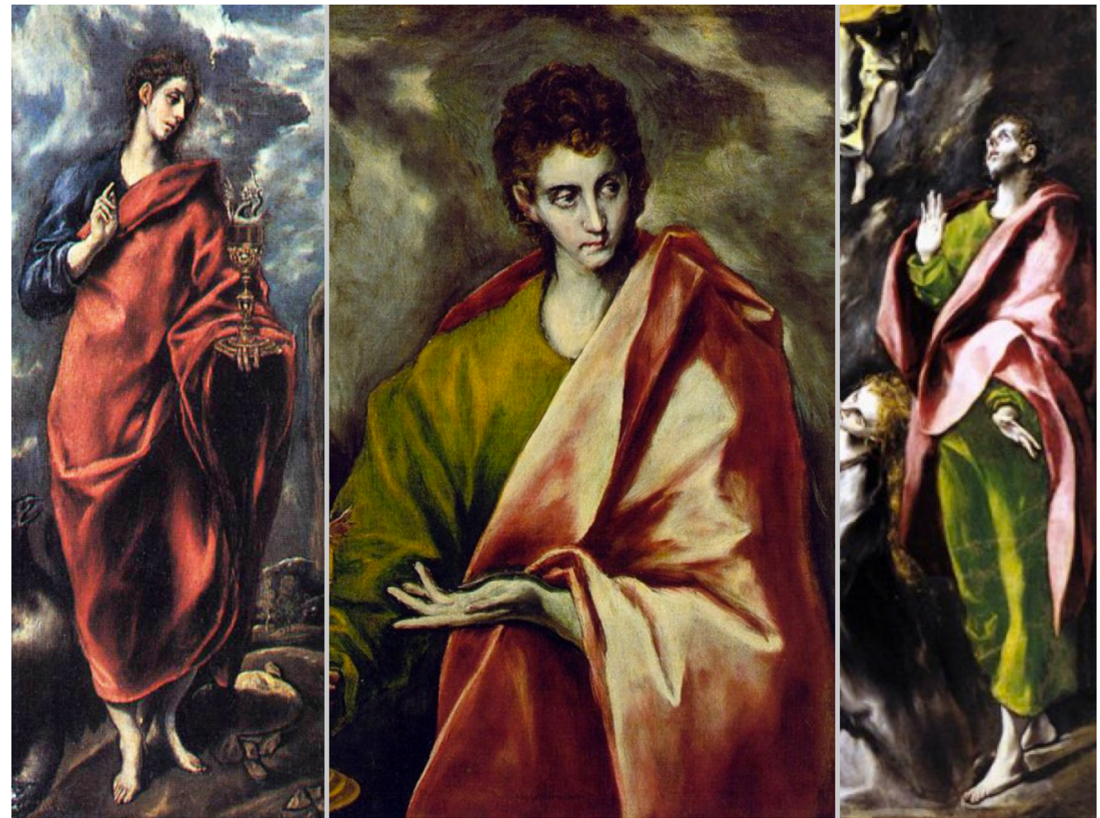

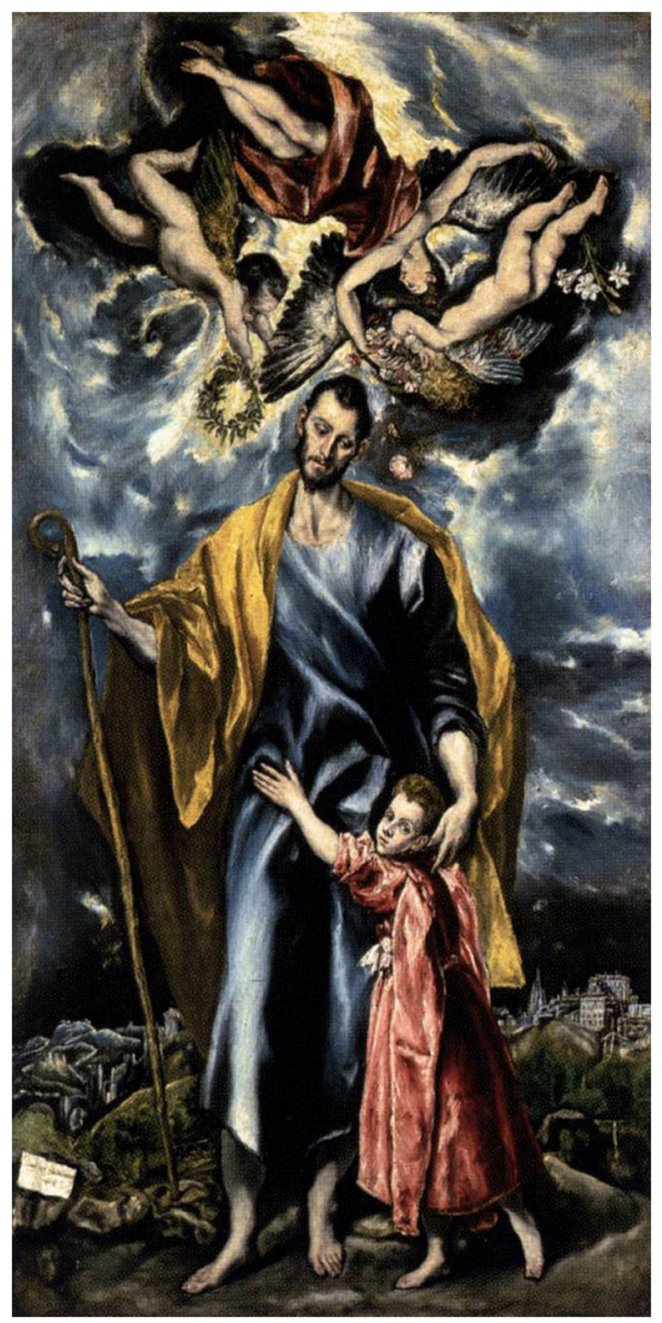

Fig. 4 St. Joseph and Christ Child, Santa Cruz Museum, Toledo

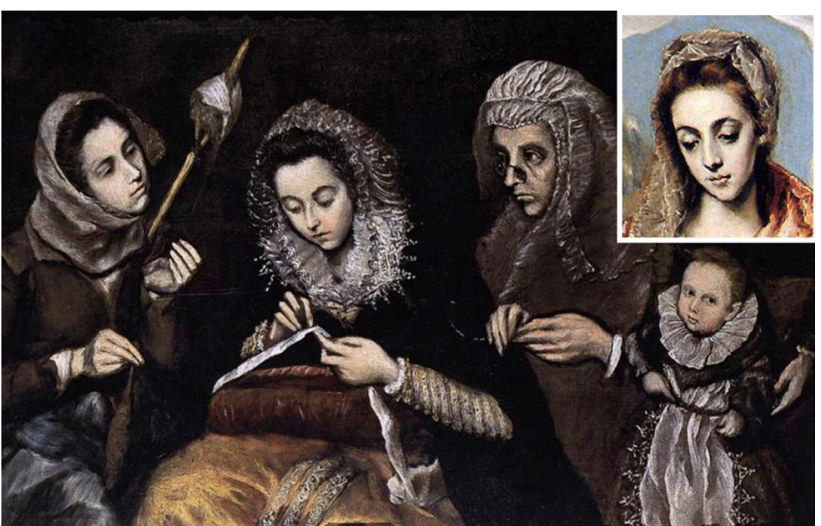

Fig. 5 Portrait of the El Greco's family. In the right upper corner, detail of the Virgin's face taken from the Holy Family (Hospital of Tavera, Toledo)

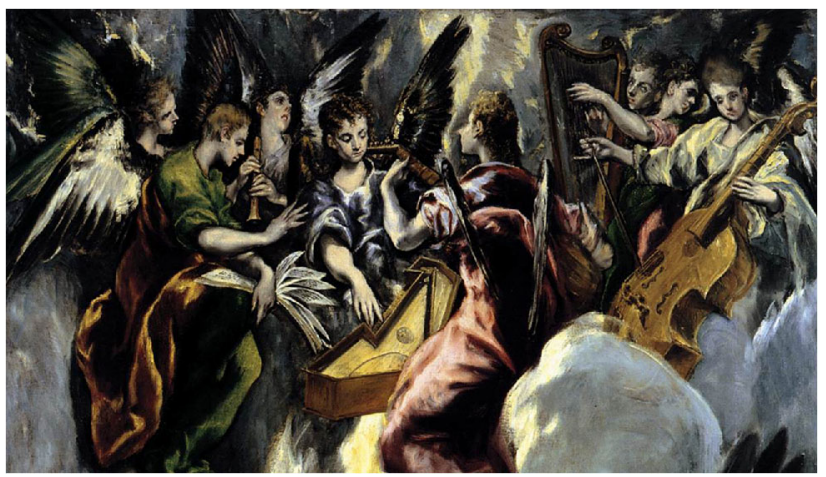

Fig. 6 Angelic concert, detail from the Annunciation, El Prado Museum, Madrid 
influence. El Greco's art has also been a source of inspiration for modern writers and music composers such as Ranier M. Rilke, Nikos Kazantzakis, and Vangelis [7].

\section{References}

1. Anstis S (2002) Was El Greco astigmatic? Leonardo 35; 2:208. Retrieved Jun 15, 2014 from: http://anstislab.ucsd.edu/files/2012/11/ 2002-Was-El-Greco.pdf
2. Cossío MB (1908) El Greco. Victoriano Suarez, Madrid

3. Kwoczyński J (2006) The figures in El Greco's paintings have signs of Marfan's syndrome. Kardiol Pol 64:1214-1220, discussion 1221-2

4. Marías F. Biografía de El Greco. Retrieved June, 18, 2014, from: http:// media.wix.com/ugd/48579f_24b0dd52115b4f7fae2397886b9338bb. pdf

5. Museo del Prado. https://www.museodelprado.es/enciclopedia/ enciclopedia-on-line/voz/greco-el-domenicos-theotocopoulos/

6. The Biography.com website (2014) El Greco. Retrieved 12:01, Jun 17, 2014, from http://www.biography.com/people/el-greco-9319123

7. Wikipedia, El Greco. Retrieved Jun 16, 2014 from: http://en. wikipedia.org/wiki/El_Greco 